\title{
BREVE NOTÍCIA SOBRE UM MANUSCRITO AUTÓGRAFO DE ALMEIDA GARRETT: OUTRA VERSÃO DE UM POEMA DE FOLHAS CAÍDAS
}

\section{BRIEF NEWS ABOUT ALMEIDA GARRETT'S AUTOGRAPH: ANOTHER VERSION OF A POEM OF FOLHAS CAÍDAS}

Ana Comandulli ${ }^{1}$

\section{RESUMO}

Relato do achado de um manuscrito autógrafo de Almeida Garrett, em espólio de António Feliciano de Castilho.

PALAVRA-CHAVE: Almeida Garrett, Folhas Caídas, manuscrito autógrafo

\section{ABSTRACT}

Report of the finding of an autograph manuscript of Almeida Garrett in Antonio Feliciano de Castilho's document collection.

KEYWORDS: Almeida Garrett, Folhas Caídas, autograph manuscript 


\section{NO ESPÓLIO DE ANTÓNIO FELICIANO DE CASTILHO}

Teófilo Braga, no capítulo dedicado exclusivamente a António Feliciano de Castilho, de seu livro A Historia do Romantismo em Portugal, publicado em 1880, desqualifica o poeta da Primavera ao ponto de afirmar que "todos os defeitos dos ultimos escriptores acham-se n'elle" (BRAGA, 1880, p. 474), decretando, inclusive que: “O juizo ácerca do seu merito se resume em uma palavra, que se conservará como a fórmula definitiva de sua individualidade litteraria: - era um árcade phostumo” (BRAGA, 1880, p. 491).

Ainda no capítulo dedicado a Castilho, Teófilo Braga afirma que a ideia do grupo do Elogio Mutuo é um atentado "contra a patria, contra a ordem politica, e até contra a moral" (BRAGA, 1880, p. 491). A expressão destacada em itálico por Teófilo Braga é uma referência clara à carta enviada por Antero de Quental a António Feliciano de Castilho, intitulada Bom senso e Bom gosto, de 1865, na qual critica, veementemente, o apoio que Castilho dava a certos poetas, afirmando que os grandes homens não sairiam, dentre outros, das arcádias ou "dos corrilhos do elogio mutuo" (QUENTAL, 1865, p. 10).

Os responsáveis pelo apagamento de António Feliciano de Castilho também tiveram um grupo que os apoiou. A história comprova que as sociabilidades mudaram de nomenclatura ao longo dos anos - arcádias, academias, sociedades -, mas que grupos sempre foram formados com o mesmo objetivo: o de firmarem-se em um determinado contexto. António Feliciano de Castilho utiliza as sociabilidades como estratégia de promoção cultural, e faz dos paratextos presentes em suas obras, tipo textual tão utilizado por ele, a continuidade ou ênfase desse trabalho, razão pela qual a Geração de 70 o critica e o ataca como organizador de uma sociedade do elogio mútuo. No entanto, Castilho conviveu com muitos escritores do seu tempo, com os quais mantinha correspondência ativa, e a eles deu a importância devida, emitindo juízos de valor em textos críticos ou em notas jornalísticas.

Em busca de uma análise menos emocional e mais distanciada no tempo do papel literário e cultural desse escritor esquecido, alguns críticos e pesquisadores vêm relendo António Feliciano de Castilho. David Mourão Ferreira, em Sobreviventes, texto apresentado no centenário da morte de Castilho (1975), já assinalava a necessidade de um estudo de sua obra no intuito de separar "o trigo do joio, que consequentemente se valorize o trigo" (MOURÃO-FERREIRA, s/d., p. 34). Outros como Fernando Venâncio e Carlos Castilho Pais, mais recentemente, também abordaram alguns aspectos positivos de sua obra tão diversificada em gênero e práticas. No Brasil, Ida Alves, que estudou um conjunto de 206 cartas de Castilho a Camilo Castelo Branco existentes no acervo do Real Gabinete Português de Leitura, e Eduardo da Cruz, inicialmente com sua tese de doutorado sobre o jornal que o autor dirigiu, a Revista Universal Lisbonense, por ela 
orientada e coorientada por Sérgio Nazar David, seguida por uma sequência de artigos publicados no Brasil e no exterior, são alguns pesquisadores que vêm se dedicando a essa tarefa à qual também nos lançamos. O grupo de pesquisadores que se reuniu para investigar o "trigo" da obra do poeta português produziu o livro Para não esquecer Castilho, publicado em 2014, pela Editora da Universidade Federal Fluminense.

Nosso envolvimento com esse universo extrapolou aquele trabalho do grupo e partimos na direção de um estudo mais detalhado dos prefácios, prólogos, notas e frontispícios que caracterizam sua obra poéti$\mathrm{ca}$, para assim descortinar o trabalho do poeta em seu tempo, em meio às transformações do século. E não foi por acaso que escolhemos o entorno da obra desse autor. Entendemos, baseados na teoria de Gérard Genette, que os elementos paratextuais e epitextuais fazem parte do prolongamento da presença de uma obra no mercado editorial, desde a consumação até a recepção, sob a forma material de livro, cartas e periódicos.

A visão castilhiana aponta para o liame indissociável entre o estado literário e o estado social. A missão do poeta era, para Castilho, manter a ligação entre o passado e o presente, para legar ao futuro o que de boa produção houvesse. Além disso, ele via a composição poética como algo lúdico, que tinha passado a ser um ofício, uma profissão, não como fruto de inspiração. Castilho promovia sim uma rede de sociabilidades por meio da qual mantinha relações literárias e pessoais importantes para seus diversos projetos, incluindo-se a promoção e o incentivo a certas escritoras de seu tempo, como temos estudado em outros trabalhos já publicados ou apresentados desde nossa tese de doutorado ${ }^{2}$.

Foi exatamente o estudo sobre um escritor que atravessou três quartos do século XIX até seu falecimento em 1875, buscando perceber como Castilho entendia a produção de poesia e sua circulação, além da rede de sociabilidades que ele articulava em cada projeto levado adiante, que nos levou a buscar mais informações e documentos literários no espólio da família Castilho, no subfundo Júlio de Castilho do Instituto de Coimbra, localizado na Biblioteca da Universidade de Coimbra, e no fundo visconde de Castilho no Arquivo Nacional da Torre do Tombo, em Lisboa. Dessa pesquisa, já divulgamos vários documentos inéditos, entre eles, para falar de um nome mais comum ao público, uma carta de Machado de Assis ao mestre Castilho (CUNHA, 2014, p. 336) e republicada em nosso livro António Feliciano de Castilho nas letras oitocentistas portuguesas: sociabilidade e difusão da escrita feminina, 2017, pela Editora Novas Edições Acadêmicas. Agora é a vez de trazermos mais um manuscrito autógrafo, descoberto no âmbito da referida pesquisa em seu espólio. Este pertenceu ao autor que entrelaçou, em alguns momentos, sua vida com a de António Feliciano de Castilho, o escritor Almeida Garrett (1799-1854). 


\section{O MANUSCRITO AUTÓGRAFO}

Por decisão testamentária, Júlio de Castilho, filho mais velho de António Feliciano de Castilho, doou os manuscritos utilizados como fonte para sua obra Memórias de Castilho ao Instituto, que hoje forma um subfundo instalado na Biblioteca da Universidade de Coimbra. Todavia, outro espólio da família Castilho encontra-se no Arquivo Nacional da Torre do Tombo - ANTT. Foi neste conjunto, sob os auspícios da CAPES, durante nossa bolsa de estágio de doutorado no exterior, que encontramos o documento publicado agora. Trata-se de um manuscrito autógrafo de um poema de Almeida Garrett, doado por sua filha, Maria Adelaide, ao segundo visconde de Castilho, Júlio de Castilho, em $1884^{3}$.

Maria Adelaide de Almeida Garrett nasceu em 12 de março de 1841, mas seu batismo só foi realizado dois meses depois, como filha natural de João Batista de Almeida Garrett. Sérgio Nazar David, em seu livro Correspondência Familiar, afirma que "Garrett lutou pela legitimação da menina desde a primeira hora, processo que só concluiu em 1851, junto com o título de Visconde, cuja segunda vida nunca se confirmou em Maria Adelaide”. (DAVID, 2012, p. 77).

Por sua vez, Júlio de Castilho ${ }^{4}$, nascido em 1841, era o filho de António Feliciano de Castilho com sua segunda esposa, Ana Carlota Vidal Xavier de Castilho. Recebeu o título de visconde de Castilho após a morte de seu pai. Na busca por manter viva a memória do poeta Castilho e de sua obra, para também dessa forma responder a Teófilo Braga e demais escritores da Geração de 70, Júlio de Castilho organizou o espólio de sua família, republicou a coleção de obras de seu pai, fazendo, mais tarde, a doação dos documentos ao Instituto, de Coimbra, e ao Arquivo Nacional da Torre do Tombo, em Lisboa.

\section{O AUTÓGRAFO}

O poema com o qual Maria Adelaide presenteou Júlio de Castilho intitula-se "Mais Rosa". Transcrevemo-lo integralmente a seguir:

\section{Mais Rosa}

Para todos tens carinhos, A ninguem mostras rigor! Que rosa es tu sem espinhos? $\mathrm{Ai}$; que não te intendo, flor.

Se a borbuleta vaidosa A desdem te vai beijar, O mais q[eu] lhe fazes, rosa, É surrir e é corar.

E quando a sonsa da abelha, Tam modesta em seu pedir, 
Te diz: "Ó rosa vermelha,

"Bem me podes acudir!

"Deixa do caliz divino

"Uma gotta só libar, ...

"Deixa, é nectar peregrino,

"Mel q[ue] eu não sei fabricar..."

Tu da lástima rendida,

De malditta compaixão,

Tu á supplica atrevida

Não sabes dizer q[eu] não.

Tanta lástimas e carinhos;

Tanto dó, nenhum rigor!

Es rosa, e não tens espinhos...

Ai, q[ue] não te intendo, flor!

Esse poema, na primeira edição de Folhas Caídas, de 1853, publicada anonimamente, em Lisboa, apresenta algumas diferenças, a começar pelo título, "Rosa Sem Espinhos" (GARRETT, 1853a, p. 51). No segundo verso da terceira estrofe, a palavra que no manuscrito é "pedir", na primeira edição está "zumbir". Os dois últimos versos também estão ligeiramente diferentes na pontuação. Na primeira edição está: "Es rosa e não tens espinhos!/Ai! que não te intendo, flor” (GARRETT, 1853a, p. 52).

A segunda edição de Folhas Caídas também é publicada em 1853, compondo a terceira parte de um volume único que, segundo os editores, se tratava de uma "segunda edição muito augmentada e correcta" (GARRETT, 1853b, p. 115) de Folhas Caídas. O poema continua tal e qual como na primeira edição anônima do mesmo ano: "Rosa sem espinhos".

Há ainda uma contrafacção carioca publicada no mesmo ano pela Typographia de N. Lobo Vianna Junior, situada na rua d'Ajuda, n. 57. Esta repete o poema tal como publicado pela editora portuguesa.

Não podemos assinalar de que época é o manuscrito autógrafo, mas podemos afirmar que se trata de uma versão até então desconhecida, pois as demais edições de Folhas Caídas publicam o poema "Rosa sem espinhos" tal como as edições originais de 1853. Além das breves alterações em pontuação, cujas exclamações sonorizam mais uma leitura oral, algo importante para o oitocentos, e da mudança do título, Garrett, ao trocar "zumbir" por "pedir" no poema "Mais rosa", pouco altera o sentido do poema. Os dois fazem referência ao som emitido pela abelha, sendo o primeiro baseado na onomatopeia e o segundo indicando uma prosopopeia. Além disso, o verbo "pedir" torna a rima mais próxima do verbo "acudir" no quarto verso da mesma estrofe.

Cabe ressaltar que Garrett lida com ambos os verbos no poema "Destino", também publicado em Folhas Caídas, aproximando seus sentidos: "Insinou alguem á abelha/ Que no prado anda a zumbir/ Se á flor 
branca ou se á vermelha/ O seu mel hade ir pedir?" (GARRETT, 1853a, p. 45). Assim, ao humanizar a abelha, que escolhe a flor, o poeta apresenta o amor como algo natural, fruto do destino. Essa "obra-prima da cristalização impessoal de paixão pessoal” (FERREIRA, 1969, p. LIV) possui uma forte natureza erótica, sobretudo pela alegoria do inseto penetrando a flor atrás de seu mel, logo associado ao percurso amoroso do próprio eu lírico: "Que eras tu meu ser, querida,/ Teus olhos a minha vida,/ Teu amor todo o meu bem.../ Ai! não m’o disse ninguem.” (GARRETT, 1853a, p. 45).

Por outro lado, "Mais Rosa", ou "Rosa sem espinhos", ao focalizar o papel da rosa, que não se nega a atender ao pedido da abelha (“Deixa do caliz divino/ 'Uma gotta só libar, ...”), cobra mais atitude, mais opinião, mais "rigor" na escolha da flor. É de fato um poema sobre o ciúme de um eu lírico que desejaria ver mais espinhos na rosa, sua amada, para afastar outros pretendentes.

De toda a sorte, os poemas de Folhas Caídas tinham uma destinatária muito especial, como indica Sérgio Nazar David em seu livro Cartas de Amor à Viscondessa da Luz:

Em 1913, na $1^{\text {a }}$ edição do folheto Garrett e as cartas de amor, Júlio Brandão mantém o silêncio em relação ao nome da suposta inspiradora das Folhas Cahidas. Mas no aditamento à $2^{\text {a }}$ edição, publicado em 1926, lança mão de uma estratégia muito curiosa: publica uma carta de Teófilo Braga reconhecendo o erro em que incorrera (ao considerar falsos os manuscritos de quem tinha notícia), publica uma das poucas cartas em que Garrett se dirige à sua correspondente pelo nome de "Rosa" e não pela inicial R., e encerra o volume um fac-símile da referida carta. (DAVID, 2004, p. 45-46)

Não sabemos informar exatamente se alguma carta acompanhava a entrega do manuscrito autógrafo. O que motivou Maria Adelaide a encaminhar o manuscrito ao filho de António Feliciano de Castilho também é desconhecido. Há apenas um fólio para dar conta de que material se tratava, abaixo transcrito:

Autographo escrito pela propria mão do Visconde de Almeida Garrett.

Offerecido por sua filha a Ex. ${ }^{\text {ma }}$ Senhora D. Maria Adelaide de Almeida Garrett a Julio de Castilho, por intermedio de Anselmo Braamcamp Freire, que m’o levou á Bibliotheca em 30 de Outubro de 1884.

Anselmo Braamcamp Freire foi um importante político, que desempenhou diversos cargos na administração nacional e municipal em Portugal, além de ser conhecido como bibliófilo, historiador e genealogista. Sua amizade com Júlio de Castilho foi confessada por ele no preâmbulo de seu livro sobre os brasões do palácio de Sintra, cuja ideia original surgiu em uma estada nessa vila justamente no outono de $1884^{5}$. 
Quanto ao poema, a própria data de composição é ignorada, o que nos impede de indicar se a versão que agora apresentamos é anterior ou posterior à publicada em Folhas Caídas. Conforme explica José Gomes Ferreira, baseado nas indicações de Gomes de Amorim, que teria examinado "o borrão da colecção" (FERREIRA, 1969, p. XXXVIII), "Folhas Caídas não passam duma colectânea de poesias de 1846 a 1853 (a aceitarmos as datas, por via de regra tão suspeitas, de Garrett" (FERREIRA, 1969, p. XL).

A paixão que nos move a escavar o espólio de António Feliciano de Castilho, um poeta esquecido pela História da Literatura, é sobretudo ressaltar o papel primordial desse poeta no campo literário português do oitocentos, mas também encontrar documentos que possam contribuir para os estudos literários portugueses. Esse, em especial, para os investigadores da poesia madura de Almeida Garrett. Esperamos, assim, também colaborar com os pesquisadores que estão preparando edições críticas das obras completas de Garrett sob coordenação da professora doutora Ofélia Paiva Monteiro.

\section{OS ORIGINAIS:}

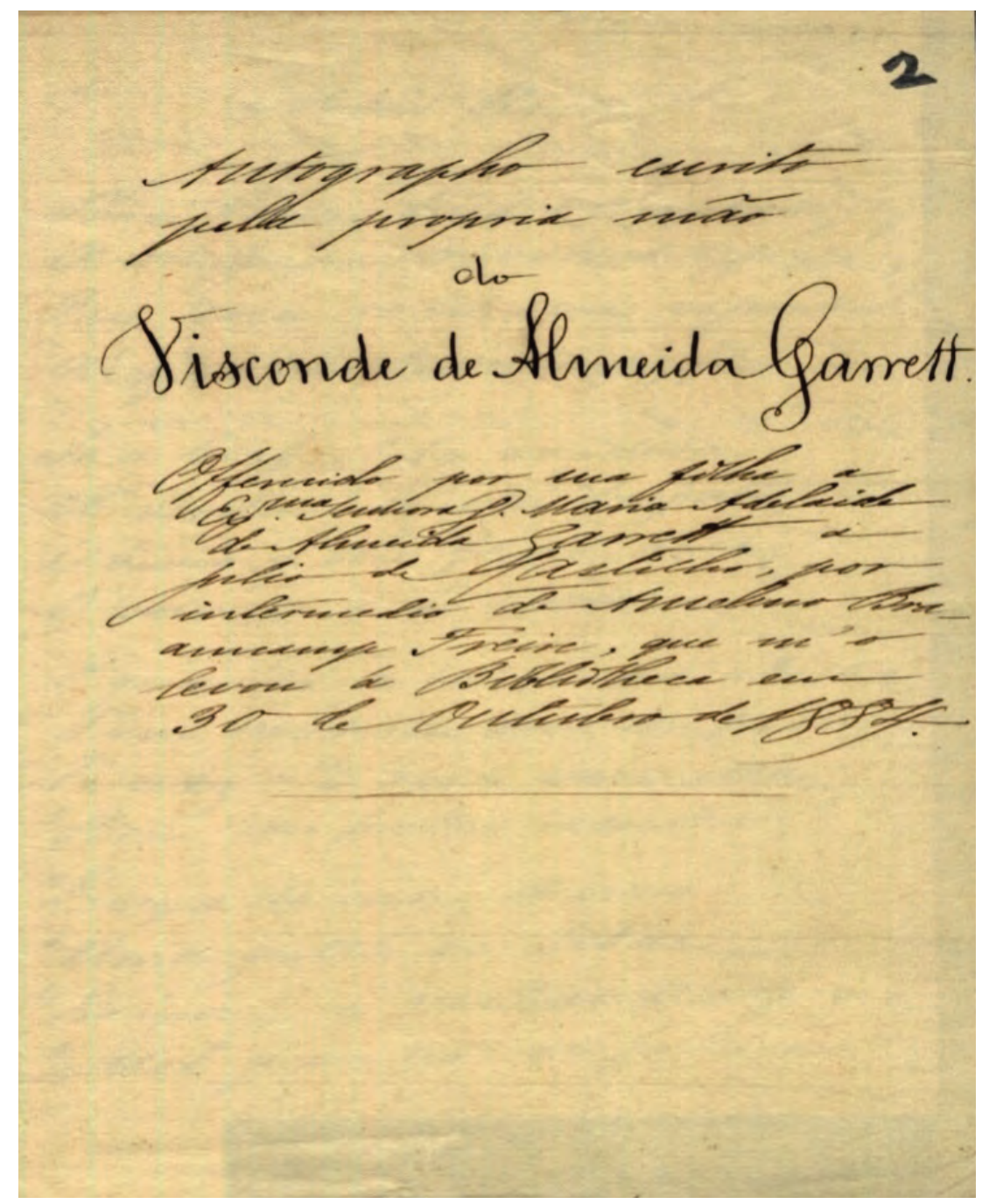


eleais Dosa

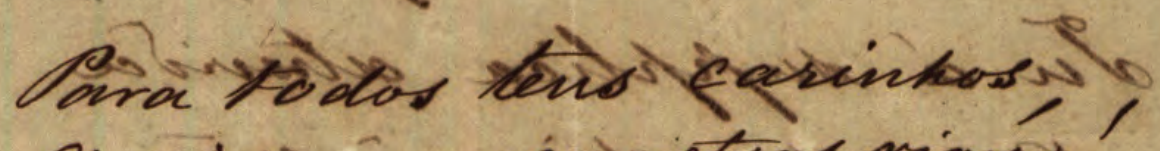

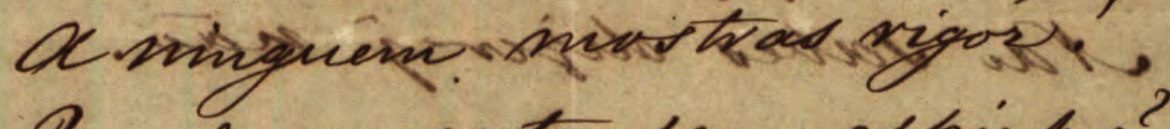
Tue rosa ed tw sem espinkos?

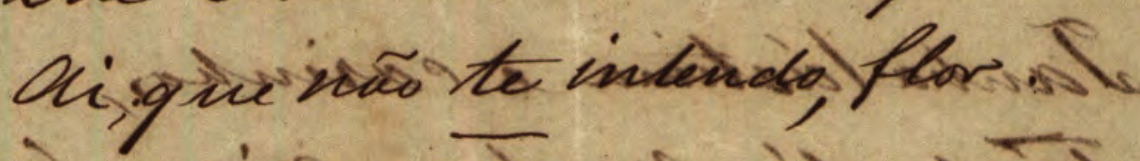

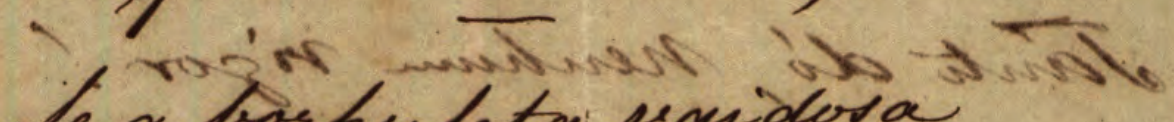
Le a borpuleta vaidosa al desdem te vai brejais's Omais, gr the yazed, Nava, E'surir e é corar.

Qquando a sonsa da abelha, Iam modrsta en sen peri, Tediz: "O'rosa vermetha, "Bem ne fodes acurir." "Leija do caliz dirino "Uma gutta do' libar,... "Deipa, e' nectar fieregrino, "Ulel' en nov seifabicar.."

158

GBPYL - Revista do NEPA/UFF, Niterói, v. 9, n.19, p. 151-161, jul.-dez. 2017 


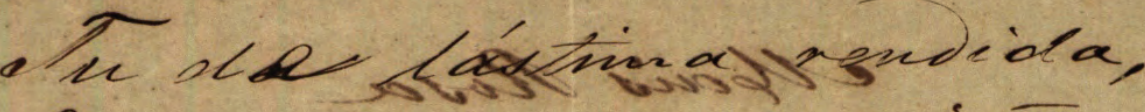
Le nabdiata amparisat,

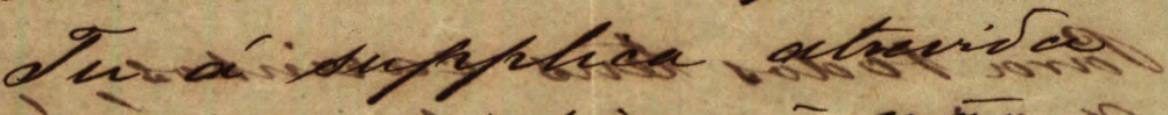

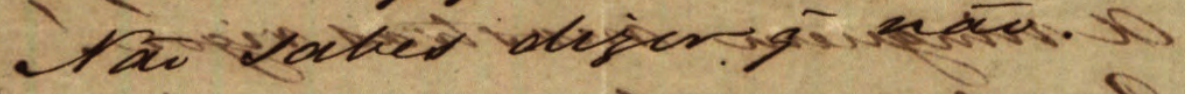

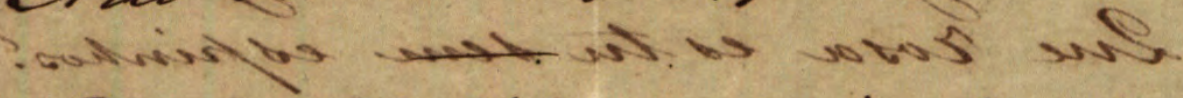

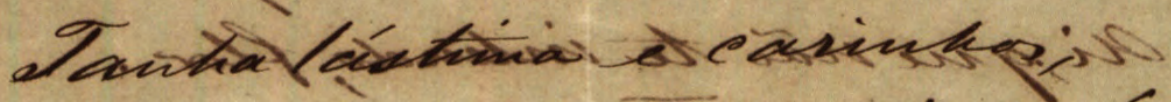

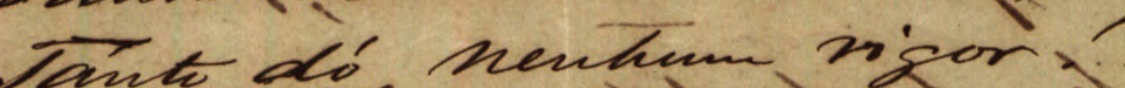
dank dés

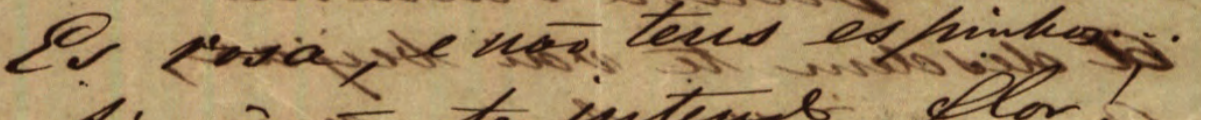

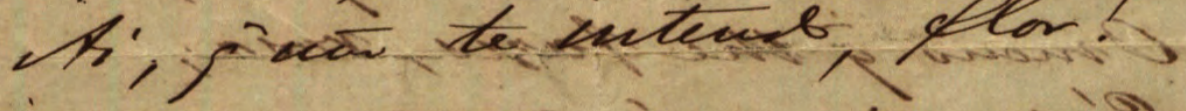
- isoners is 3 issastos

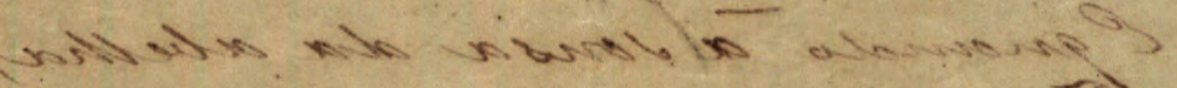

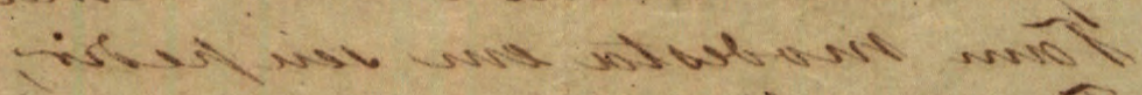

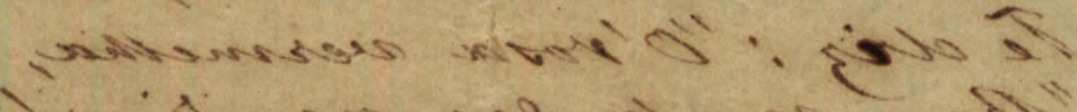
I.

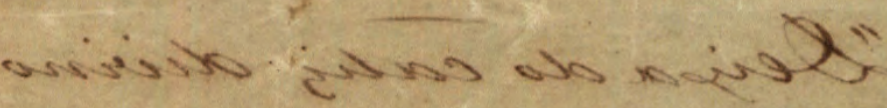

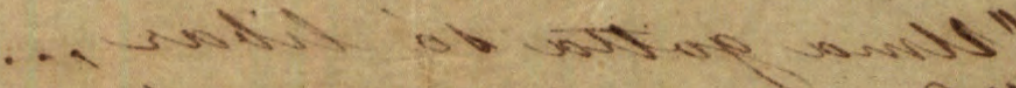

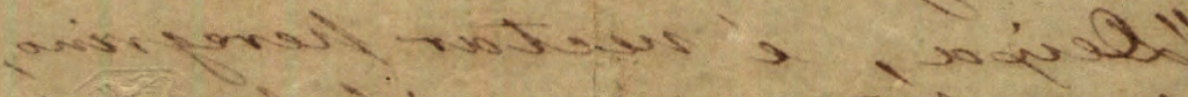

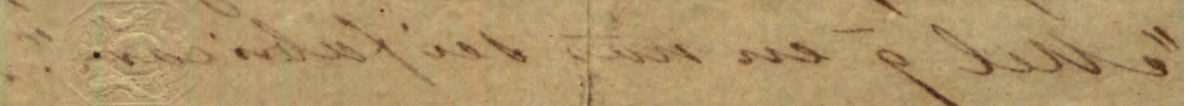




\section{REFERÊNCIAS BIBLIOGRÁFICAS}

ALVES, Ida Ferreira. "Cartas de António Feliciano de Castilho a Camilo Castelo Branco no Real Gabinete Português de Leitura do Rio de Janeiro". Convergência Lusíada, Rio de janeiro, v. 22, p. 177-200, 2006.

BRAGA. Teófilo. História da Literatura Portuguesa - V - O Romantismo. Mem Martins: Publicações Europa-América, s.d.

CRUZ, Carlos Eduardo Soares da. Felicidade pela Imprensa: Romantismo na Revista Universal Lisbonense de A.F. de Castilho (1842 - 1845). Tese de doutorado defendida em junho de 2013 no Instituto de Letras da UFF.

CUNHA, Ana Cristina Comandulli da. Presença de A.F. de Castilho nas letras oitocentistas portuguesas: sociabilidades e escrita feminina.Tese de doutorado defendida em 29 de agosto de 2014 no Instituto de Letras da UFF.

DAVID, Sérgio Nazar. Correspondência Familiar. Lisboa: Imprensa Nacional-Casa da Moeda, 2012.

. Cartas à Viscondessa da Luz. Lisboa: 7 Letras, 2004.

FERREIRA, Anselmo Braamcamp. Brasões da Sala de Sintra. Livro Primeiro. 2. ${ }^{a}$ ed. Coimbra: Imprensa da Universidade, 1921.

FERREIRA, José Gomes. "Introdução”. in: GARRETT, Almeida. Folhas Caídas. 2a ed. Lisboa: Portugália editora, 1969.

GARRETT, Almeida. Folhas Cahidas. Lisboa: Em Casa da Viúva Bertrand e Filhos, 1853a. (edição anônima)

. Folhas Cahidas. Lisboa: Imprensa Nacional, 1853b.

. Folhas Cahidas. Rio de Janeiro: Typographia de N. Lobo Vianna Junior, 1853.

GENETTE, Gérard. Seuils, Editions du Seuil, 1987.

Recebido para publicação em 13/10/2017

Aprovado em 28/10/2017

\section{NOTAS}

1Doutora em Estudos de Literatura (Literatura comparada) pela Universidade Federal Fluminense - UFF - com ênfase no escritor António Feliciano de Castilho e sua presença nas letras oitocentistas portuguesas: sociabilidade e difusão da escrita feminina; Mestre em Literatura Portuguesa pela Universidade Federal do Rio de Janeiro - UFRJ; Bacharel em Letras - Português/Literatura da Língua Vernácula pela Faculdade de Letras da UFRJ; Pesquisadora do Polo de Pesquisa sobre Relações Luso-Brasileiras do Real Gabinete Português de Leitura, Investigadora Colaboradora do Centro de Estudos Clássicos da Universidade de Lisboa; Técnica em Assuntos Educacionais na Universidade Federal do Estado do Rio de Janeiro - UNIRIO. Os interesses em pesquisa são literatura portuguesa oitocentista, mercado literário, sociedades literárias no oitocentos, escrita feminina, rede de escritoras femininas.

2 Presença de A. F. de Castilho nas letras oitocentistas portuguesas: sociabilidade e escrita feminina. Tese defendida em 29/09/2014. UFF, Niterói. Orientação Profa. Dra. Ida Alves e Coorientação de Prof. Dr. Sérgio Nazar David. 
3 Manuscrito autógrafo localizado no ANTT, caixa 62, mç 7, nº 8.

4 Júlio de Castilho (1840-1919) foi jornalista, poeta, escritor, historiador e político. Além da recolha do espólio da família Castilho e a manutenção da memória de seu pai, notabilizou-se por seu trabalho de olisipógrafo, deixando obras fundamentais nesse campo de estudos.

5 Freire conta que, após uma visita a Sintra no outono de 1884, resolveu escrever pequenos artigos sobre as famílias da Sala dos Brasões do paço da Vila, acompanhados por "desenhos dos veados do tecto da sala das armas" feitos por Maria Francisca de Meneses e Maria Amália de Sousa Botelho, e "quem os passava às chapas de madeira era outro amigo, o visconde Júlio de Castilho, hábil desenhador, e paciente revisor de provas e original” (FREIRE, 1921, p. 4). Talvez tenha sido num desses momentos que Braamcamp Freire tenha entregado o manuscrito. 